\title{
Refractory bleeding due to duodenal varices
}

\section{Obada Tayyem ${ }^{\mathrm{a}}$, Timothy Krilla, Arya Bagherpour ${ }^{\mathrm{b}}$}

The University of Texas Medical Branch, USA

A 57-year-old female with a history of alcoholic cirrhosis presented with melena. Initial upper endoscopy performed at an outside facility revealed a possible ulcer in the second part of the duodenum (D2), treated with 3 hemoclips. The patient was transferred to our institution for further management. Repeat endoscopy revealed a large varix in D2 with active bleeding and adjacent prior hemoclips (Fig. 1). She was referred for emergency transjugular intrahepatic portosystemic shunt (TIPS). Preprocedural computed tomography angiography demonstrated large paraduodenal collaterals and duodenal varices (DV) corresponding to what was seen on endoscopy (Fig. 2). She underwent TIPS and coil embolization of the DV. She continued to experience bleeding, requiring upsizing of the TIPS. Further bleeding prompted endoscopic cyanoacrylate glue injection directly into the varix (Fig. 3). After an initial response, the bleeding resumed and was only controlled after repeat coil embolization of residual paraduodenal collaterals feeding the DV. Unfortunately, she succumbed to sepsis and fungemia despite receiving appropriate antibiotics and antifungals.

DV are a complication of portal hypertension and are considered ectopic varices. These are portosystemic collaterals in locations besides the gastroesophageal region and represent $2-5 \%$ of variceal bleeding. Seventeen percent of ectopic variceal

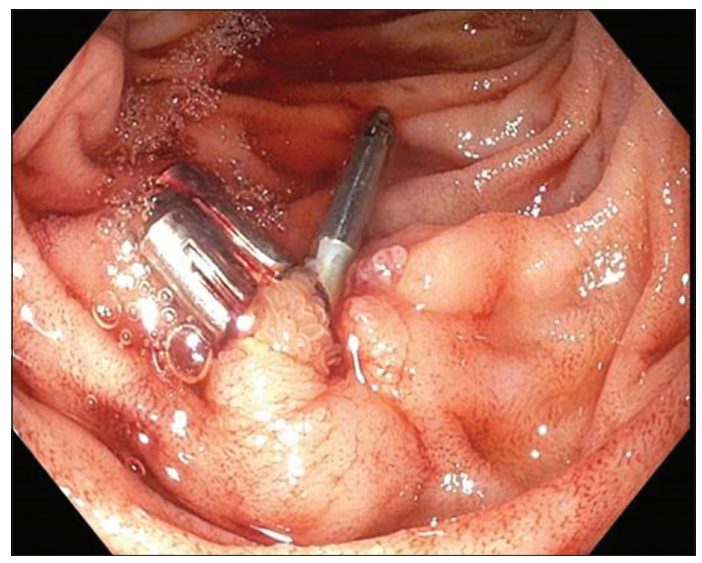

Figure 1 Hemoclips placed over the varix seen in the second part of the duodenum

Department of a Gastroenterology and Hepatology (Obada Tayyem, Timothy Krill); ${ }^{b}$ Radiology (Arya Bagherpour), The University of Texas Medical Branch, USA

\section{Conflict of Interest: None}

Correspondence to: Timothy Krill, 301 University Blvd., Galveston, TX 77555-0570, USA, e-mail: tskrill@utmb.edu

Received 29 July 2018; accepted 7 August 2018; published online 14 September 2018

DOI: https://doi.org/10.20524/aog.2018.0309

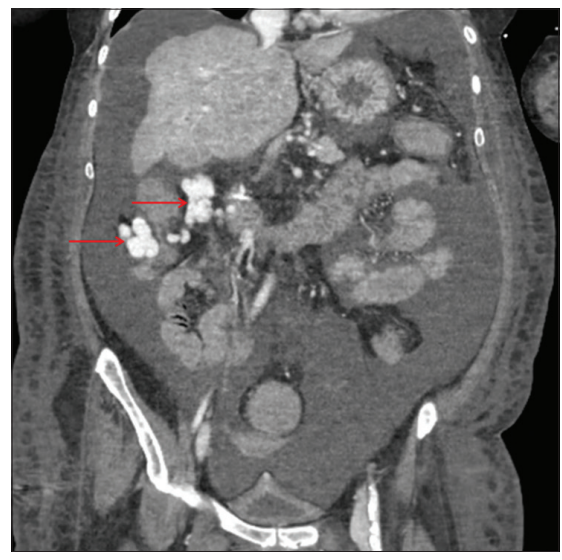

Figure 2 Computed tomography of abdomen with presence of large paraduodenal varices (arrows)

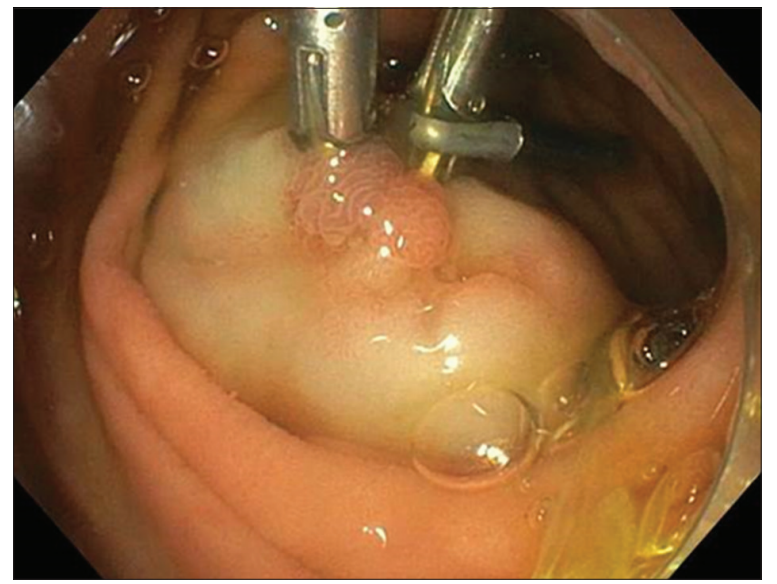

Figure 3 Duodenal varix after cyanoacrylate injection

bleeding is from DV [1]. The most common site for DV is the duodenal bulb, followed by D2 [2]. The mortality rate for acute bleeding is up to $40 \%$ [3]. Because of its rarity, there have been no randomized trials concerning the management of this condition. DV are challenging to treat and can be fatal.

\section{References}

1. Norton ID, Andrews JC, Kamath PS. Management of ectopic varices. Hepatology 1998;28:1154-1158.

2. Wang CS, Jeng LB, Chen MF. Duodenal variceal bleedingsuccessfully treated by mesocaval shunt after failure of sclerotherapy. Hepatogastroenterology 1995;42:59-61.

3. Khouqeer F, Morrow C, Jordan P. Duodenal varices as a cause of massive upper gastrointestinal bleeding. Surgery 1987;102:548-552. 